\title{
Acesso ao Transplante de Medula Óssea por meio do Tratamento Fora do Domicílio (TFD)
}

\author{
Access to Bone Marrow Transplantation Through Out-of-Home Treatment
}

\section{Silvana Maria Escorsim * Amanda Rachel Rosa**}

RESUMO: O presente artigo é resultado de um estudo sobre o acesso dos usuários ao Transplante de Medula Óssea (TMO) do Complexo Hospital de Clínicas da UFPR, no ano de 2018, com a utilização dos recursos do Tratamento Fora do Domicílio (TFD) e objetivou analisar o impacto desses recursos na permanência dos usuários fora de seu domicílio para a realização do TMO. Utilizou-se a metodologia quanti-qualitativa, através da aplicação da pesquisa documental e de campo. Os resultados quantitativos mostraram que $51,9 \%$ acessaram satisfatoriamente os recursos do TFD, correlatos aos princípios doutrinários do Sistema Único de Saúde, contudo, 48,1\% dos usuários acessaram parcialmente ou não tiveram acesso aos mesmos, o que impactou desfavoravelmente, segundo dados qualitativos, suscitando adversidades no período de tratamento fora do domicílio, o que evidencia a omissão de alguns municípios na concessão integral do direito ao TFD.

Palavras chave: Direitos Sociais; Direito à Saúde; Transplante de Medula Óssea; Tratamento Fora do Domicílio; Serviço Social.

ABSTRACT: This article is the result of a study on users access to the Bone Marrow Transplant (BMT) of the Hospital de Clínicas Complex of UFPR, in 2018, using the resources of Treatment Outside the Home (TFD) and aimed to analyze the impact of these resources on the permanence of users outside their home to perform the BMT. The quantitative and qualitative methodology was used, through the application of documentary and field research. The quantitative results showed that $51.9 \%$ accessed the TFD resources satisfactorily, correlated to the doctrinal principles of the Unified Health System, however, 48.1\% of the users partially accessed or did not have access to them, which had an unfavorable impact, according to data qualitative, causing adversities in the treatment period outside the home, which shows the omission of some municipalities in the full concession of the right to the TFD.

Key words: Social Rights; Right to health; Bone marrow transplant; Out-of-home treatment; Social Work.

\footnotetext{
* Doutora em Serviço Social pela PUCSP; Professora adjunta da Câmara do Curso de Serviço Social da UFPR Setor Litoral. Professora tutora da Residência Multiprofissional Integrada em Atenção Hospitalar do Complexo Hospital de Clínicas da UFPR.

** Bacharel em Serviço Social pela Pontifícia Universidade Católica do Paraná (2016). Ex-residente no programa do Serviço Social em Oncologia e Hematologia do Complexo do Hospital de Clínicas da Universidade Federal do Paraná. Especialista em Atenção Hospitalar pelo CHC - UFPR.
} 


\section{Introdução}

Durante o período da República Velha, o primeiro modelo assistencial de saúde no Brasil, chamado de sanitarismo campanhista, pautava-se numa prática assistencial de ações sanitárias pontuais voltadas para grupos específicos, bem como, para os interesses políticoeconômicos vigentes na época de ascensão do capitalismo. Tal modelo, implementado por Oswaldo Cruz, tinha ainda um caráter policial e punitivo com a atuação dos denominados "guardas sanitários", sem considerar até a década de 30, ações de educação sanitária e promoção de saúde (GIOVANELLA, 2008).

No decorrer dos anos, mudanças impulsionaram a criação de Caixas de Aposentadorias e Pensões (CAPs) e Institutos de Aposentadorias e Pensões (IAPs) para os trabalhadores formais ${ }^{1}$, sendo estes contribuintes do modelo previdenciário vigente. Entretanto, estes contemplavam parcela mínima de trabalhadores brasileiros, sendo a população majoritária alijada do trabalho formal, estando à mercê da caridade.

O modelo assistencial vigente no Brasil, anterior a Carta Magna de 1988, traduziu-se pela fragmentação entre a prevenção e o tratamento, numa visão biologizante das doenças, desconsiderando a integralidade do atendimento e, por conseguinte, a promoção e proteção da saúde frente aos riscos e agravos sanitários. Não obstante, fez-se presente, ainda, a lógica assistencial de caráter hospitalocêntrico/curativista nas ações de saúde, de viés mercantil, que tardiamente incorporou os trabalhadores informais e domésticos, numa gestão do sistema que se caracterizou como centralizadora.

Nesta perspectiva, a Reforma Sanitária foi impulsionada pelos anseios da população vulnerável e desprotegida, bem como de representantes do cenário acadêmico e profissional da área da saúde da época, em ideais que iriam contrapor-se ao modelo vigente. Assim, a

\footnotetext{
${ }^{1}$ Os antigos institutos de Aposentadoria e Pensões (IAPs), autarquias por categorias profissionais criadas em 1930 pelo presidente Getúlio Vargas, substituíram as caixas de Aposentadorias e Pensões (CAPs), fundadas a partir de 1923. Estes institutos foram fundidos e deram origem, em 1966, ao Instituto Nacional de Previdência Social (INPS), englobando todos os empregados com carteira assinada, os quais recebiam assistência médicaprevidenciária desse instituto. Em 1974, foi criado o Instituto Nacional de Assistência Médica e Previdência Social (INAMPS), para atender aos segurados do INPS. Após a Constituição Federal de 1988, que definiu o Sistema Único de Saúde (SUS), houve a transição dos serviços médicos previdenciários para a assistência à saúde do Ministério da Saúde representada sistema Unificado e Descentralizado de Saúde (SUDS), "um convênio entre o Inamps e os governos estaduais", seguido da incorporação do INAMPS pelo Ministério da Saúde. Em 1990, o INPS foi fundido ao Instituto de Administração Financeira da Previdência e Assistência Social (IAPAS), originando o Instituto Nacional do Seguro Social (INSS); e o INAMPS, extinto em 1993, foi o alicerce, desde 1990, do atual SUS para prover atenção à saúde a todo o povo brasileiro, independente de contribuição ao INSS, acabando com a figura do indigente na saúde (OLIVEIRA, 2012).
} 
partir do Movimento da Reforma Sanitária foi desencadeado o primeiro marco para o desenvolvimento de uma política de saúde de acesso universal, cujo marco central foi a VIII Conferência Nacional de Saúde (1986), a qual propôs a universalidade, a integralidade e a equidade como princípios doutrinários fundamentais.

A promoção de integralidade emerge a partir da intenção em unificar e combater a fragmentação nos atendimentos de saúde que, até então, não era combatida. Em 1988 a Carta Magna brasileira foi promulgada e, consequentemente, o SUS foi regulamentado pela lei no 8.080/90² (Lei Orgânica da Saúde), que definiu o atual modelo operacional do sistema de saúde brasileiro.

Como vieses propulsores de um sistema de saúde universal destacam-se a equidade e a integralidade de ações, serviços e setores. Estes buscam a completude no atendimento aos usuários do sistema. Parte do entendimento e aplicabilidade do conceito de integralidade é a abrangência existente nas demandas e ferramentas disponíveis para subsidiar o atendimento em todos os determinantes. (GIOVANELLA, 2008)

Uma demanda a ser salientada é a necessidade de o usuário acessar o Transplante de Medula Óssea ${ }^{3}$, um procedimento de alta complexidade executado em hospital com atendimento em nível terciário de atenção e uma ferramenta fundamental para o seu acesso é o Tratamento Fora do Domicílio (TFD).

Segundo a Deliberação no 034 de 11 de maio de 1999 da Comissão Intergestores Bipartite - CIB-PR ${ }^{4}$

\begin{abstract}
O Tratamento Fora do Domicílio é o meio que permite aos usuários do SUS o acesso a atendimentos de que necessitam, não disponíveis em seu município de origem e desde que esgotadas todas as possibilidades locais de tratamento. O TFD só será autorizado quando houver garantia de atendimento no município de referência, com horário e data definidos previamente. A referência de pacientes a serem atendidos pelo TFD deve ser explicitada na PPI de cada município.
\end{abstract}

\footnotetext{
${ }^{2}$ Brasil. Lei no 8.080 de 19 de setembro de 1990. Dispõe sobre as condições para a promoção, proteção e recuperação da saúde, a organização e o funcionamento dos serviços correspondentes e dá outras providências. Disponível em: http://www.planalto.gov.br/ccivil_03/leis/l8080.htm

${ }^{3}$ Segundo a Associação Brasileira de Transplante de Órgãos (ABTO): Medula óssea é um tecido líquido que ocupa o interior dos ossos e que produz os componentes do sangue: as hemácias, que são responsáveis pelo transporte de oxigênio, os leucócitos, que fazem parte do sistema de defesa do corpo, e as plaquetas, que atuam na coagulação do sangue. E o Transplante de Medula Óssea é a substituição de uma medula óssea doente por células de uma medula sadia, com o objetivo de reconstituição de uma nova medula (ABTO, 2020. n.p.).

${ }^{4}$ SESA/COSEMS/PR. Comissão Intergestores Bipartite do Paraná. Deliberação no 34 de 11 de maio de 1999. Disponível em: https://www.saude.pr.gov.br/Pagina/CIBPR-Comissao-Intergestores-Bipartite-do-Parana
} 
O TFD é regulamentado pela Portaria n. 55 de 24 de fevereiro de $1999^{5}$ e segundo o Ministério Público do PR - MPPR (SILVA, 2008):

\begin{abstract}
Considera ser da responsabilidade do município, as providências necessárias para agendamento da consulta ou do procedimento prescrito ao paciente em local mais próximo da origem, devendo ainda viabilizar os meios e recursos necessários para garantir transporte e diárias considerando que os valores das diárias destinadas aos usuários que necessitam utilizar do TFD não pode ser inferior ao valor de $\mathrm{R} \$ 24,75$ (MS Portaria 055) para prevenir possíveis prejuízos à saúde coletiva, decorrentes da não observância desses parâmetros, estipulados pelo Ministério da Saúde, para custeio do TFD (SILVA, 2008, np).
\end{abstract}

Diante deste sistema de atendimento à população, o Complexo Hospital de Clínicas da Universidade Federal do Paraná (CHC-UFPR) é um centro de referência em Transplante de Medula Óssea (TMO). Evidencia-se que, atualmente, no Brasil existem apenas 75 equipes especializadas com condições para realizar este procedimento e estas equipes estão distribuídas em 09 dos 26 Estados brasileiros mais o Distrito Federal, segundo o Registro Brasileiro de Transplantes (2018, p.14), motivo pelo qual os usuários atendidos do setor de TMO do CHC-UFPR são oriundos de vários Estados.

A Associação Brasileira de Transplante de Órgãos (ABTO, 2018) estima que sejam realizados mais de três mil procedimentos por ano, entre autólogos (1.827) e alogênicos 6 (1.235).

Parte significativa deste processo são as intervenções realizadas pelo Serviço Social do TMO do CHC-UFPR, cuja intenção é investigar os aspectos sociais, históricos, econômicos e culturais de usuários e familiares, com o objetivo de promover o acesso aos bens e serviços das políticas públicas, necessários para o tratamento. Esta intervenção profissional desencadeia um conjunto de ações que permite a realização de encaminhamentos aos

\footnotetext{
5 MINISTÉRIO DA SAÚDE. Portaria no 55 de 24 de fevereiro de 1999. Disponível em: https://bvsms.saude.gov.br/bvs/saudelegis/sas/1999/prt0055_24_02_1999.html

${ }^{6}$ Segundo o Registro Nacional de Doadores Voluntários de Medula Óssea (REDOME) existem dois tipos de transplante de medula óssea: alogênico e autólogo: Transplante alogênico é aquele no qual as células precursoras da medula provêm de outro indivíduo (doador), de acordo com o nível de compatibilidade do material sanguíneo. A primeira opção é sempre pela medula de um irmão. Se o indivíduo não tem irmão ou este não é compatível, também se verifica a compatibilidade com a mãe e o pai. Se não há um doador aparentado com boa compatibilidade, procura-se um não aparentado compatível. Este tipo de transplante também pode ser feito a partir de células precursoras de medula óssea obtidas do sangue de um cordão umbilical. Transplante autólogo é aquele no qual as células precursoras da medula óssea provêm do próprio indivíduo transplantado (receptor). As células da medula ou do sangue periférico do próprio paciente são coletadas e congeladas para uso posterior. Esse tipo de transplante é usado basicamente para doenças que não afetam a qualidade da medula óssea, ou seja, aquelas que não têm origem diretamente na medula ou quando a doença já diminuiu a ponto de não ser mais detectada na medula (estado de remissão), (REDOME, 2020).
} 
benefícios sociais e previdenciários, avaliação da infraestrutura adequada para abrigar o usuário/paciente após a alta, tanto no período que compreende o pré-TMO, pós-TMO imediato e a permanência na cidade (nos casos de usuários em TFD), tanto quanto no retorno ao município de origem, além de atividades de suporte social voltadas a estes e aos seus cuidadores durante o tratamento.

Durante o período de pré-TMO, o usuário se desloca em idas e vindas para consultas e exames antes do procedimento. Neste período, o mesmo pode se hospedar em local sem quarto isolado, o que facilita e barateia a permanência na cidade de Curitiba-PR, considerando-se as diferenças do custo de vida das regiões do Brasil. Em alguns casos, o usuário e seu acompanhante chegam para a consulta no CHC-UFPR apenas com as passagens de vinda e retorno, sem qualquer recurso financeiro subsidiado pelo município de origem. Alguns chegam ao serviço com a promessa do pagamento das diárias do TFD, quando de seu retorno à cidade de origem e outros sem o conhecimento deste direito que poderia garantir o suporte financeiro.

O período de permanência fora do domicílio para o TMO pode durar mais de 100 dias a partir da data de realização do procedimento. Assim, definido e realizado o transplante, durante os primeiros 30 dias, período variável dependendo da condição clínica, o usuário permanece internado em isolamento e segundo registros públicos, um dado relevante para este estudo é a média diária dos custos para o SUS, com internação em intercorrência póstransplante no CHC, que em 2018, foi de $\mathrm{R} \$ 1$ 1.649,96 (AUDITASUS, 2018). Pode-se perceber que este procedimento é considerado de alta complexidade.

Após este período, o usuário recebe alta da internação e segue em acompanhamento ambulatorial para realizar exames e receber infusão medicamentosa. Então, neste momento, é crucial que o mesmo fique em local adequado em quarto privativo, em isolamento e rigorosa condição salubre próximo ao CHC-UFPR, devido ao quadro de baixa imunidade, e também para que não tenha despesas com transporte o qual, se utilizado, deve primar pelo isolamento. Este período pode chegar a 90 dias ou mais, dependendo das intercorrências clínicas.

No que se refere ao instrumento legal do TFD a sua execução está condicionada a disponibilidade orçamentária Municipal/Estadual, portanto, sem a previsão destes recursos a permanência do paciente fora do domicílio para o tratamento pode ser precarizada. Nesta perspectiva, a desassistência dos recursos do TFD torna-se um problema relevante a ser estudado. 
Diante disso, o/a Assistente Social tem como principal atribuição atender as expressões da questão social presentes na área da saúde, em articulação com as demais políticas públicas e espaços de promoção de cidadania e da garantia de direitos dos pacientes. Segundo a Carta Magna brasileira, em seu Art. 196: "A saúde é direito de todos e dever do Estado, garantido mediante políticas sociais e econômicas que visem à redução do risco de doença e de outros agravos e ao acesso universal e igualitário às ações e serviços para sua promoção, proteção e recuperação (BRASIL, 1988).

No Serviço Social, a Lei de Regulamentação da Profissão ${ }^{7}$ estabelece no seu artigo 4ำ como competências do assistente social: "orientar indivíduos e grupos de diferentes segmentos sociais no sentido de identificar recursos e de fazer uso deles no atendimento e na defesa de seus direitos".

Em suma, é pertinente ao Assistente Social que atua no serviço de TMO de destino, na alta e média complexidade no SUS, a aproximação com a política de acesso a saúde e o conhecimento sobre as especificidades e desafios da execução deste direito nos diferentes Estados e Municípios.

O presente estudo teve como o objeto as questões ligadas ao TFD, sua execução, ausência ou irregularidade deste recurso, o que demanda inúmeros esforços e desdobramentos para manutenção do usuário e de seu acompanhante, os quais se encontram em um momento de fragilidade de saúde e de vida, experienciadas no trabalho social realizado no decorrer da Residência Multiprofissional em Serviço Social em OncologiaHematologia junto aos usuários submetidos ao TMO no CHC da UFPR.

É necessária a contribuição para a socialização de informações pertinentes ao acesso ao Transplante de Medula Óssea (TMO) no CHC-UFPR por meio do TFD e a compreensão acerca de como a efetivação ou não do acesso ao TFD impacta na condição de permanência do usuário fora do domicílio no período do processo de TMO.

\section{Metodologia}

\footnotetext{
7 BRASIL. Lei no 8.662 de 07 de junho de 1993. Dispõe sobre a profissão de Assistente Social e dá outras providências. Disponível em: http://www.planalto.gov.br/ccivil_03/leis/l8662.htm
} 
Utilizou-se, neste estudo, dados quantitativos e qualitativos para a apreensão do objeto de investigação, tratando-se, portanto, de uma pesquisa quanti-qualitativa. (CHIZZOTTI apud MARTINELLI, 1999, p.36).

Os pressupostos da pesquisa qualitativa adotam métodos e técnicas de pesquisa própria. Ao passo que a abordagem quantitativa serve de fundamento ao conhecimento produzido pela pesquisa qualitativa e não deve ser oposta a esta, "ambas devem sinergicamente convergir na complementaridade mútua, sem confinar os processos e questões metodológicas a limites que atribuam os métodos quantitativos exclusivamente ao positivismo ou os métodos qualitativos ao pensamento interpretativo" (Idem, 1999, p.36).

Foi considerado para este estudo todo o usuário submetido ao TMO no CHC- UFPR no ano de 2018. Os critérios de exclusão desta pesquisa foram: a não localização do mesmo e a moradia localizada a menos de $50 \mathrm{~km}$ do CHC-UFPR, o que desconfigura o TFD, o óbito, a recusa do participante e o não assentimento do Termo de Consentimento Livre e Esclarecido (TCLE).

A pesquisa foi aprovada pelo Comitê de Ética em Pesquisa ${ }^{8}$ - CEP do CHC-UFPR, sob o parecer consubstanciado do referido CEP e a aplicação do questionário após apresentação do objetivo da pesquisa, com aceitação e aplicação do TCLE assentido pelos participantes.

Foi utilizada a pesquisa documental junto ao Sistema de Informação Hospitalar (SIH) da UFPR para o levantamento demográfico de dados, como também, a pesquisa de campo utilizou-se da aplicação do instrumento questionário com perguntas fechadas e uma aberta. A pesquisa de campo foi estruturada pelo Google Forms e aplicada via Whatsapp; esses dados em conjunto com os levantamentos quantitativos da pesquisa documental foram tabulados e sofreram análise estatística. A pergunta semi-estruturada dos questionários foi analisada e interpretada a partir da técnica da análise de conteúdo? .

"A pesquisa documental recorre a fontes diversificadas, sem tratamento analítico, tais como tabelas estatísticas, relatórios, documentos oficiais e etc" (FONSECA, 2002, p. 32). As informações buscadas no SIH foram o número de transplantes realizados no ano de 2018 , gênero do paciente, idade, origem, endereço e telefone. Nos arquivos específicos do serviço

\footnotetext{
8 UFPR-CHC. Comitê de Ética em Pesquisa (CEP). CAAE: 18880719.5.0000.0096 - Parecer consubstanciado no 3.575.827.

${ }^{9}$ A análise de conteúdo é um conjunto de técnicas de análise das comunicações. Não se trata de um instrumento, mas de um leque de apetrechos; ou, com maior rigor, será um único instrumento, mas marcado por uma grande disparidade de formas e adaptável a um campo de aplicação muito vasto: as comunicações (BARDIN, 2011, p.37).
} 
social, buscaram-se os dados do responsável legal nos casos em que o usuário tivesse idade inferior a 18 anos, composição familiar, renda per capita, qualidade de segurado Instituto Nacional do Seguro Social (INSS) e benefício/auxílio acessado.

O questionário foi elaborado com 22 perguntas estruturadas para captar o acesso e utilização do TFD e os dados foram submetidos à análise estatística; contou com uma pergunta aberta que, após análise, suscitou três categorias de análise, a saber: Categoria $\mathrm{n}^{\circ} 1$ Atendimento TFD na origem; Categoria $n^{\circ} 2$ - Atendimento burocrático, moroso e irregular; Categoria $n^{\circ} 3$ - Não atendimento. Os participantes foram elencados por algarismos arábicos de 01 a 27, por ordem de resposta.

A aplicação do questionário se deu por meio eletrônico, fator decisivo, em especial, porque os participantes da referida pesquisa são provenientes de variados Estados brasileiros. Uma alternativa disponível para criação de formulários eletrônicos online é a plataforma Google Forms, ferramenta que oferece suporte para a criação de formulários personalizados e apresentação de dados.

\section{Resultados e discussão}

$\mathrm{Na}$ pesquisa documental (SIH) levantou-se que 94 usuários/pacientes foram submetidos ao TMO no decorrer do ano de 2018 no CHC-UFPR, sendo um dado importante que, neste mesmo período, 3.091 TMO foram realizados no território brasileiro. Dos 26 Estados brasileiros mais o Distrito Federal, 16 Estados enviaram pacientes para TMO no CHCUFPR.

Considerando que os pacientes do serviço de Transplante de Medula Óssea (STMO) são provenientes de vários Estados do Brasil apuramos que a origem predominante é o Estado do Paraná com 46.8\%, seguido de Santa Catarina com 21.3\%, Bahia com 5.3\%, Ceará, Minas Gerais e Goiás com 4\% cada; Piauí, Mato Grosso e Alagoas com 2.1\% cada; Rio Grande do Sul, Roraima, São Paulo, Amazonas, Distrito Federal, Maranhão e Mato Grosso do Sul com 1.1\% cada. O gênero predominante é o masculino em $67 \%$ dos casos e o feminino em $33 \%$, dentre os quais $40.4 \%$ possuem idade inferior a 18 anos e $59.6 \%$ com mais de 18 anos.

Dentre os 94 pacientes submetidos ao TMO, aplicaram-se os critérios de exclusão que correspondeu a 13 pacientes que residem a menos de 50 (cinquenta) km do hospital, o que desconfigurou o perfil para o TFD, do qual 1 (um) foi a óbito. Restaram 81 pacientes com 
perfil TFD, excluindo-se mais 19 pacientes que foram a óbito até o momento da coleta de dados, a qual ocorreu nos meses de setembro e outubro de 2019, restando 62 usuários com perfil para a aplicação do questionário na pesquisa de campo.

Ao enviar o TCLE e o questionário, 9.7\% dos pacientes não foram localizados. E 45.2\% aceitaram participar, enviando-nos as suas respostas. Outros $45.2 \%$ ignoraram o contato e não responderam ao instrumento de coleta de dados.

Os pacientes que não aceitaram participar da pesquisa são dos Estados de Minas Gerais, Piauí, Alagoas, Rio Grande do Sul, Roraima, São Paulo, Amazonas, Distrito Federal e Maranhão.

Considerou-se a orientação, desde a origem, como um fator decisivo para acesso ao direito do usuário ao tratamento fora do domicílio. Portanto, por meio deste estudo, constatou-se que as orientações para a abertura do processo do TFD no município de origem foram realizadas para apenas $74,1 \%$ dos pesquisados, enquanto, $25,9 \%$ dos respondentes declararam não ter recebido orientações.

Um ato básico como comprovar endereço e documentos de identificação para abrir o processo do TFD foi solicitado a apenas $81,5 \%$ dos pesquisados, contrapondo-se a $18.5 \%$ que declararam não ter levado documento e comprovante de endereço na secretaria de saúde da cidade de origem.

É fundamental para o usuário ou responsável legal reconhecer que o TFD é um direito regulamentado por lei. Assim sendo, levantou-se que $70.4 \%$ dos pesquisados declararam reconhecer o direito, diante $29,6 \%$ que declarou desconhecer. Dado este que se manifesta na prática cotidiana profissional, porque pacientes sem orientação desde a origem, chegam ao Serviço Social do TMO apreensivos e desconhecendo a responsabilidade do município de origem quanto sua manutenção fora do domicílio no período do tratamento.

Entre $63 \%$ dos pesquisados foi declarado conhecimento sobre a cobertura do TFD, o qual deve garantir o transporte seja este terrestre, aéreo ou fluvial de acordo com a necessidade do usuário em relação a sua condição clínica ou de acesso ao meio de transporte. Contudo, 37\% dos pesquisados declarou desconhecer esta cobertura. Em relação ao conhecimento sobre o valor das diárias que, segundo a portaria específica, é no mínimo de R\$ 24,75 por pessoa, $77.8 \%$ dos pesquisados tem conhecimento, enquanto $22.2 \%$ revelaram desconhecimento.

Um fato relevante sobre as diárias do TFD é o de que os valores fixados vigoram desde 24 de fevereiro de 1999, sem nenhuma atualização; mais de duas décadas se passaram sem 
os devidos ajustes inflacionários anuais, evidenciando que o valor da diária do TFD é inferior às necessidades financeiras atuais.

Considerando-se que transporte, estadia e alimentação são essenciais para a manutenção do usuário em TFD para TMO, levantou-se que:

Quadro no 1: Meios de transporte utilizados pelos usuários e familiares

\begin{tabular}{|c|c|c|c|c|c|}
\hline Transporte & Aéreo & $\begin{array}{ll}\text { Veículo } & \text { da } \\
\text { Prefeitura } & \end{array}$ & Veículo Próprio & $\begin{array}{l}\text { Transporte } \\
\text { coletivo } \\
\text { interestadual }\end{array}$ & $\begin{array}{l}\text { Três tipos de } \\
\text { transporte }\end{array}$ \\
\hline Aéreo & $33.3 \%$ & & & Ambos 3.7\% & \\
\hline $\begin{array}{ll}\text { Veículo } & \text { da } \\
\text { prefeitura } & \end{array}$ & & $29.6 \%$ & Ambos $3.7 \%$ & & \\
\hline Veículo Próprio & & & $14.8 \%$ & & \\
\hline $\begin{array}{l}\text { Transporte } \\
\text { coletivo } \\
\text { interestadual }\end{array}$ & & Ambos 3.7\% & & $7.4 \%$ & \\
\hline $\begin{array}{l}\text { Três tipos de } \\
\text { transporte. }\end{array}$ & & & & & $\begin{array}{l}3,7 \% \\
\text { (próprio, da } \\
\text { prefeitura e } \\
\text { aéreo). }\end{array}$ \\
\hline
\end{tabular}

Fonte: pesquisa das autoras, 2020.

Apurou-se que $33.3 \%$ dos pesquisados utilizou o transporte aéreo, seguido de $29,6 \%$ que utilizou o veículo da prefeitura e $14,8 \%$ que utilizou o veículo próprio; 7,4\% transporte coletivo interestadual. O restante dos pesquisados relatou uso de mais de um meio de transporte, dentre eles 3,7\%, transporte aéreo e transporte coletivo interestadual; $3,7 \%$ usou veículo da prefeitura e transporte coletivo interestadual; 3,7\% veículo próprio e da prefeitura 3,7\% utilizou três meios distintos, veículo próprio, veículo da prefeitura e transporte aéreo, em todo o período do tratamento.

No quesito transporte, em $76,9 \%$ dos casos o custeio do transporte foi pago pela secretaria de saúde do município de origem; em $11,5 \%$ dos casos foram utilizados recursos próprios do pesquisado sem ressarcimento; em 7,7\% a secretaria de saúde proporcionou o custeio parcial combinado com os recursos próprios do pesquisado com ressarcimento; 3,8\% secretaria de saúde proporcionou algum recurso combinado com recursos próprios do usuário, sem ressarcimento. Destaca-se que $11,5 \%$ não acessaram o recurso TFD para o transporte.

Considerando-se o longo processo de TMO, conforme supracitado, o período de permanência fora do domicílio evidenciou que para $44.4 \%$ dos pesquisados foi de um a três 
meses; para $44.4 \%$ de quatro a seis meses; $7.4 \%$ permaneceram menos de um mês e para $3.7 \%$ de dez a doze meses.

No que se refere a este período de permanência em Curitiba para o procedimento de TMO, 40.7\% dos pesquisados alugou um local próximo ao Hospital de Clínicas; $18.5 \%$ ficaram em casa de apoio conveniada pelo município; $14.8 \%$ utilizaram casa de apoio filantrópica que oferece acomodação para crianças; $11.1 \%$ utilizaram casa de apoio filantrópica que oferece acomodação para adultos; 7,4\% pagaram hotel ou pensão; $7.4 \%$ hospedaram-se na casa de parentes ou conhecidos na cidade.

Quadro no 2: Renda familiar declarada

\begin{tabular}{|l|l|}
\hline Salário Mínimo Nacional & Percentual \\
\hline Renda inferior ao salário mínimo & $7,4 \%$ \\
\hline Um salário mínimo & $18,5 \%$ \\
\hline Um a dois salários mínimos & $33,3 \%$ \\
\hline Dois a três salários mínimos & $14,8 \%$ \\
\hline Três a quatro salários mínimos & $11,1 \%$ \\
\hline Quatro ou mais salários mínimos & $14,8 \%$ \\
\hline
\end{tabular}

Fonte: pesquisa das autoras, 2020

Durante todo o período fora do domicílio para o tratamento, recursos financeiros próprios são empregados pelo usuário ou responsável legal. Considerando esta realidade, levantou-se que 33,3\% a renda familiar é superior a um e inferior a dois salários mínimos. Para $51,9 \%$ dos pesquisados não houve privação financeira no período fora do domicílio, contudo, para $48,1 \%$ dos pesquisados foi declarada privação com necessidade de ajuda financeira ou doação de alimentos no período fora do domicílio para o transplante.

Portanto, a periodicidade do repasse dos valores do recurso TFD foi crucial para manutenção destes usuários e para 59.3\% dos pesquisados ocorreu em dia; de modo irregular em $25.9 \%$ dos casos e para $14.8 \%$ dos pesquisados o repasse foi inexistente.

Levou-se em consideração a condição de subsistência da família do pesquisado que permaneceu na origem e levantou-se que três grupos familiares são compostos por um indivíduo. Seis grupos familiares são compostos por dois indivíduos. Seis grupos familiares são compostos por três indivíduos, oito grupos familiares são compostos por quatro indivíduos. Três grupos familiares são compostos por cinco indivíduos. Um grupo familiar é composto por oito indivíduos. 
Quanto à origem da renda familiar, em $22,2 \%$ dos pesquisados é proveniente de trabalho formal com registro em carteira. $18,5 \%$ dos pesquisados declarou não possuir renda. Em 18,5\% a renda familiar é proveniente do auxílio-doença (INSS). Em 11,1\% a renda familiar é proveniente de aposentadoria. Em 7,4\% a renda familiar é proveniente de duas fontes, aposentadoria e trabalho formal (registro em carteira de trabalho).

Em 7,4\% a renda familiar é proveniente de duas fontes: auxílio-doença e trabalho formal com registro em carteira. Em 3,7\% a renda familiar é proveniente de duas fontes, aposentadoria e trabalho informal. Em 3,7\% a renda familiar é proveniente de três fontes, auxílio-doença, aposentadoria e trabalho formal com registro em carteira. Em 3,7\% a renda familiar é proveniente de duas fontes: Benefício de Prestação Continuada (BPC) e aposentadoria. Em 3,7\% a origem da renda é proveniente de trabalho informal.

Considerando-se a composição familiar e renda declarada pelos pesquisados, somada a composição familiar declarada de todos os 27 participantes da pesquisa chega-se a média de 2.3 pessoas por família, com o mínimo de uma pessoa e o máximo de oito pessoas. A partir da soma dos valores declarados da renda familiar de todos os participantes, a média da renda fixou-se em $\mathrm{R} \$ 859,00$ por família.

Observada a média de 2.3 pessoas por família e a média da renda familiar de $\mathrm{R} \$ 859,00$, obteve-se a média da renda per capita por família de $\mathrm{R} \$ 268,00$. Esta renda per capita obtida foi impulsionada para baixo pelos pesquisados que não possuem renda. Segundo Instituto Brasileiro de Geografia e Estatística (IBGE) ${ }^{10}$, a renda per capita nacional em 2018 foi registrada em $\mathrm{R} \$ 1.373,00$, contudo o centro aponta disparidade de renda de Estado para Estado que varia de $\mathrm{R} \$ 841,00$ à $\mathrm{R} \$ \mathbf{1 . 6 6 0 , 0 0}$. Os participantes deste estudo declararam renda per capita abaixo da média nacional, mesmo considerando a disparidade regional referida pelo $\mathrm{IBGE}^{11}$.

Um dado importante a considerar é que segundo IBGE $^{12}$ a informalidade atingiu $41,1 \%$ da população ocupada, o que equivale a 38,4 milhões de pessoas sem registro de

10 IBGE. IBGE divulga o rendimento familiar per capita 2018. Disponível em: https://agenciadenoticias.ibge.gov.br/agencia-sala-de-imprensa/2013-agencia-de-noticias/releases/23852ibge-divulga-o-rendimento-domiciliar-per-capita-2018

11 Idem a nota $\mathrm{n}$ ㅇ 09.

12 IBGE. Desemprego cai para 11,9\% na média de 2019; informalidade é a maior em 4 anos.. Disponível em: https://agenciadenoticias.ibge.gov.br/agencia-noticias/2012-agencia-de-noticias/noticias/26741-desemprego-cai-para-11-9-namedia-de-2019-informalidade-e-a-maior-em-4-anos 
trabalho formal em 2018. Em quatro anos, o país perdeu 3,7 milhões de postos de trabalho com carteira assinada (SILVEIRA, 2019).

A partir do momento em que recebe a alta hospitalar, o usuário obtém a liberação para o retorno à cidade de origem. A pesquisa considerou que a espera gera um custo diário para a subsistência. Em relação ao tempo de espera do pesquisado, obteve-se que 33,3\% retornou para origem imediatamente, pois utilizou recurso próprio; $40.7 \%$ um dia, pois aguardava liberação de transporte pelo município; $18.55 \%$ dois dias; 3.7\% quatro dias; 3.7\% sete dias aguardando liberação de transporte do município.

A condição clínica do usuário no momento do retorno à origem é importante e compreende inúmeras orientações e recomendações com relação aos cuidados e precauções, devido à imunidade baixa e para segurança do pós-transplantado. Neste sentido, a equipe médica determina que o mesmo seja removido em transporte isolado, no intuito de evitar contato com agentes patogênicos nocivos a recuperação, prevenindo-se novas intercorrências e internações.

O acesso ao transporte isolado, devido à baixa imunidade, foi alcançado por $55.6 \%$ dos pesquisados, contudo, $44.4 \%$ liberados para retorno a cidade de origem, viajaram dividindo o transporte com outras pessoas, sujeitando-se a sorte e exposição aos agentes patogênicos, uma vez que o transporte da prefeitura ou público não foi adequado às exigências do pós-transplante.

A pergunta semi-estruturada do questionário referia-se a experiência do usuário em relação ao TFD e a condição de permanência para o TMO. As respostas possibilitaram a identificação de três categorias, para as quais se procedeu à técnica de análise de conteúdo: Categoria $n^{\circ} 1$ - Atendimento TFD na origem; Categoria $n^{\circ} 2$ - Atendimento burocrático, moroso e irregular; Categoria $n^{\circ} 3$ - Não atendimento.

Categoria $\mathrm{n}^{\circ}$ 01: Atendimento TFD na Origem.

\begin{tabular}{|l|l|}
\hline RESPOSTAS & PESQUISADOS \\
\hline “Foi legal". & PARTICIPANTE N01 e №02. \\
\hline “Boa". & PARTICIPANTE N03 e №04. \\
\hline "Foi muito boa". & PARTICIPANTE N²1. \\
\hline “Foi ótima". & PARTICIPANTE N²2. \\
\hline “Ótimo". & PARTICIPANTE N²5 e №26. \\
\hline “Foi boa, bem tranquilo e tivemos um ótimo atendimento". & PARTICIPANTE N¹8. \\
\hline $\begin{array}{l}\text { “Permanecemos desde o dia 12/01/2018 até 24/10/2018 na casa de } \\
\text { apoio Ideal (nome da instituição) antes da TMO em quarto normal e } \\
\text { depois em quarto isolado. Só temos o que agradecer a todos tanto do } \\
\text { Hospital de clínicas como da assistência social do nosso município pelo }\end{array}$ & \\
\hline
\end{tabular}




\begin{tabular}{|l|l|}
\hline $\begin{array}{l}\text { atendimento nada deixando a desejar. Nesses casos de TFD o mais } \\
\text { complicado e ficar longe da família e do trabalho, por mais que tenha } \\
\text { ajuda com hospedagem e transporte os gastos sempre vem". }\end{array}$ & \\
\hline $\begin{array}{l}\text { "Gostei muito, pois me ajudaram bastante e ainda ajuda com custo de } \\
\text { passagem e hospedagem muito útil esse empenho deles e preocupação } \\
\text { do tratamento de nossas crianças". }\end{array}$ & PARTICIPANTE №12. \\
\hline $\begin{array}{l}\text { “Fui muito bem atendido, considero necessário para os pacientes em } \\
\text { tratamento". }\end{array}$ & PARTICIPANTE №13. \\
\hline "Tudo foi muito rápido, fiquei satisfeita como fomos atendidos". & PARTICIPANTE №16. \\
\hline "Tudo ocorreu da melhor forma, pra mim foi tudo excelente". & PARTICIPANTE №17. \\
\hline “Muito ruim, mas no final valeu apena um ensinamento para vida". & PARTICIPANTE №15. \\
\hline "Foi difícil, mas consegui superar". & PARTICIPANTE №19. \\
\hline “Cansativo". & PARTICIPANTE №23. \\
\hline "Razoável". & PARTICIPANTE №24. \\
\hline “Mal". & PARTICIPANTE №27. \\
\hline "Não sei responder". & PARTICIPANTE № 20. \\
\hline & \\
\hline
\end{tabular}

Conforme os relatos da Categoria $\mathrm{n} 01$ a maioria dos participantes manifestaram experiências com declarações elogiosas ao serviço de TFD na origem, consistindo em uma percepção positiva, com serviço ágil sem deixar a desejar, o que conferiu tranquilidade aos usuários no período fora do domicílio para o processo de TMO. A experiência negativa foi registrada pelos participantes de № 15; № 19; № 23 e № 27, sem que os mesmos oferecessem detalhes sobre os aspectos que determinaram as suas insatisfações.

Estas declarações convergem com os princípios fundamentais do SUS ${ }^{13}$, a Universalidade que determina o direito ao acesso às ações e serviços de saúde a todos os cidadãos brasileiros, a Integralidade que se destina a conjugar as ações direcionadas à materialização da saúde como direito e como serviço e a Equidade em que as ações e serviços devem ser oferecidos aos cidadãos, independentemente do nível de complexidade que cada caso requeira e independente da região em que o usuário resida, resultando em uma experiência favorável para $51,9 \%$ dos participantes. Contudo, $7,4 \%$ dos pesquisados expressaram que seu acesso foi insatisfatório, com exceção do relato do participante nํ20 que não soube responder.

Categoria $\mathrm{n}^{\circ}$ 02: Atendimento burocrático, moroso e irregular.

\begin{tabular}{|l|l|}
\hline RESPOSTAS & PESQUISADOS \\
\hline “O TFD do meu município não era eficiente em relação a me ajudar. & PARTICIPANTE No05. \\
Sempre havia uma grande lentidão no processo e muitas burocracias. & \\
Os funcionários do setor não são nada atenciosos ou educados. Recebi & \\
o dinheiro da ajuda de custo do município depois que já havia dois & \\
meses de transplante, os outros meses foram quase 10 meses depois & \\
porque o TFD sempre alegava problemas nos preenchimentos dos & \\
\hline
\end{tabular}

13 Idem a nota no02. 
papéis e isso tornou um grande atraso no recebimento do dinheiro. Se não fosse ajuda de familiares ou amigos não teria como me manter. Obs. Só posso fazer elogios positivos para todo o setor, tanto do $15^{\circ}$ andar como no $4^{\circ}$ andar. São profissionais supercompetentes e sempre prestativos. Tive um excelente cuidado pré, durante e pós transplante. Minha queixa é, quando surge dúvidas no momento que já estamos no lugar de origem e não temos acesso aos médicos com mais facilidade. $\mathrm{Na}$ grande maioria das vezes são as enfermeiras que dão algum suporte".

"Temos de sair de nossa cidade de ônibus que fica cerca de $220 \mathrm{~km}$ de distância por conta própria e fica muito cansativo, e depois sempre um pouco demorado o processo de passagens para retorno para cidade de origem e o não pagamento por estadia na cidade de Curitiba quando fazemos as consultas o que normalmente levam de 3 a 4 dias".

"Não recebemos informações prévias, só quando internada para o TMO em conversas com enfermeiras e outros acompanhantes passamos a ter conhecimento sobre o TFD e pudemos usufruir deste auxílio para a permanência em Curitiba".

"Em relação ao TFD foi uma negação, pois tive que arcar com todas minhas necessidades diárias financeiras, só tendo reembolso das diárias após 7 meses que retornei pra minha cidade de origem".

"O TFD da nossa cidade é muito enrolado tivemos vários problemas, não tivemos ressarcimentos com gastos do transporte próprio q tivemos q ir na consulta das primeiras vezes".

PARTICIPANTE №08.

PARTICIPANTE №09.

PARTICIPANTE №10.

PARTICIPANTE №11.

Categoria $n^{\circ} 3$ - Não atendimento.

\begin{tabular}{|l|l|}
\hline RESPOSTAS & PESQUISADOS \\
\hline “Minha experiência em relação ao TFD foi bastante exaustiva, tanto & PARTICIPANTE No06. \\
emocional quanto física. Precisei recorrer judicialmente para conseguir & \\
uma casa de apoio porque o município se negou a fornecer, após & \\
conseguir, acabei por ficar apenas uma semana porque a casa não & \\
oferecia suporte mínimo para um paciente pós transplante de medula & \\
óssea e logo depois segui para casa de parentes que fica a & \\
aproximadamente 40 km do hospital. A partir de então, utilizei apenas & \\
recurso próprio até a alta de retorno para casa, contando com ajuda de & \\
familiares. De uma forma geral foi bastante desgastante, mas, graças a & \\
Deus, a amigos e familiares, tudo deu certo e isso é o mais importante". & \\
\hline "Para mim ruim, pois não tive ajuda sempre que recorremos foi & PARTICIPANTE No14. \\
negado". & \\
\hline
\end{tabular}

Nas análises das categorias $\mathrm{n} 002$ e $\mathrm{n} 003$ os relatos manifestam experiências que explicitaram a ausência de orientações prévias à viagem para o TMO, o que promoveu um processo burocrático, problemático, ineficiente, com casos de atendimento rude por parte dos funcionários na origem, ausência de transporte sem o devido ressarcimento das custas para este fim, o que obrigou ao uso de transporte com recursos do próprio pesquisado.

Os aspectos citados pelos pesquisados são: a demora na emissão de passagens para retorno à origem, repasses financeiros com morosidade de até sete meses após a alta para retorno à origem, irregularidades ou inexistência de acesso ao direito. Exaustão, tanto emocional quanto física do pesquisado. Necessidade de judicialização devido à negativa do 
município de origem e mesmo com o posterior deferimento a favor do usuário, houve a contratação de casa de apoio com suporte inadequado, o que resultou na mudança de local.

Estes relatos apontam que no TFD persistem atendimentos residuais, pontuais e seletivos, com também, em alguns casos, a omissão municipal em oferecer o recurso, o que descumpre os preceitos da Carta Magna e fere os princípios doutrinários fundantes do SUS. Portanto, caracterizando a desassistência por parte dos entes federados frente às necessidades dos pesquisados, o que correspondeu a uma experiência desfavorável para $40,7 \%$ dos participantes, registrada na coleta dos dados quantitativos.

\section{Considerações finais}

Considerando-se a singularidade do pesquisado e sua subjetividade com relação a percepção do direito ao recurso, evidenciou-se com a pesquisa a disparidade no que se refere ao cumprimento do TFD, para garantia de acesso à saúde, conforme verificado em resultados estatísticos e na análise interpretativa destes. $\mathrm{O}$ acesso integral e igualitário dos recursos para o Tratamento Fora do Domicílio não foi alcançado.

A parcela de pesquisados que passou pelo processo de TMO com a efetivação integral do recurso demonstrou impacto favorável e tranquilidade no decorrer do período fora do domicílio, o que viabilizou o tratamento e recuperação da saúde.

Em contrapartida, a parcela de pesquisados teve o acesso parcial ou inexistente do recurso demonstrou impacto desfavorável, com a materialização de privação financeira, inquietudes e adversidades no decorrer do período fora do domicílio, o que maximizou as

preocupações e acúmulo de dificuldades para além do foco central que deveria ser o tratamento e o restabelecimento da saúde.

Neste sentido, evidencia-se a necessidade de maior comprometimento dos municípios com relação à efetivação dos recursos para o TFD. O acesso integral do recurso aumenta a possibilidade do usuário ter uma alimentação adequada, acomodações e transporte com condições salubres mais próximas ao ideal no período fora do domicílio para TMO.

Como já citado neste estudo, o custo médio diário de internação em intercorrências clínicas do TMO no CHC-UFPR, no ano de 2018, foi de R\$ 1.649,96. Quanto menos intercorrências houver neste período, aumentam as chances de uma reabilitação bem 
sucedida no pós-transplante e aperfeiçoa-se a aplicação dos recursos públicos em favor dos brasileiros. A atual diária do TFD tem um valor defasado de $\mathrm{R} \$ 24,75$; contudo, demonstrouse significativa para os usuários no decorrer do processo de TMO e pequena se comparada ao valor imensurável da vida.

Enfatiza-se a necessidade de maior divulgação e repasse de informações aos usuários do Sistema Único de Saúde, bem como aos municípios sobre as especificidades da intervenção e tratamento do Transplante de Medula Óssea e, principalmente, no que se refere ao direito constitucionalmente garantido para o seu usufruto.

Segundo IAMAMOTO (2001) um dos maiores desafios que o Assistente Social vive no presente está na sua capacidade de decifrar a realidade e construir propostas de trabalho criativas e capazes de preservar e efetivar direitos, a partir das demandas emergentes no cotidiano. O desafio desta questão se apresenta para o Serviço Social, no cotidiano profissional, com a exigência de abordagens que defendam de modo intransigente a vida, a saúde e os direitos da população usuária e na formulação de estratégias para seu enfrentamento.

\section{Referências bibliográficas}

ABTO. Associação Brasileira de Transplante de Órgãos. Disponível em:

< https://sbtmo.com.br/indicadores $>$. Acesso em 12 de novembro de 2019.

AUDITASUS. Auditoria Analítica em Internações SUS. Painel custo médio de Internações SUS por especialidade (UF x Hosp.). Disponível em:

$<$ https://auditasus.com.br/internacoes-sus/custo/custo-medio-intern-sus/custo-medio-deintern-sus-por-especialidade-mun?ano=2018\&mes=12\&uf=PR\&nomemun=CURITIBA-PR $>$.

Acesso em 19 de janeiro de 2020.

BARDIN, L. Análise de Conteúdo. São Paulo: Edições 70, 2011.

BRASIL. Constituição Federal Brasileira de 1988, também disponível em $<$ http://www2.camara.leg.br/legin/fed/consti/1988/constituicao-1988-5-outubro-1988322142-publicacaooriginal-1-pl.html >. Acesso em 16 de julho de 2019.

BRASIL. Lei no 8.080, de 19 de setembro de 1990. Lei Orgânica da Saúde. Dispõe sobre as condições para a promoção, proteção e recuperação da saúde, a organização e o funcionamento dos serviços correspondentes e dá outras providências. Brasília, set. 1990. Disponível em: < http://www.planalto.gov.br/ccivil 03/leis/L8080.htm >. Acesso em 16 de junho de 2018. 
BRASIL. Código de ética do/a assistente social. Lei 8.662/93 de regulamentação da profissão. - 9. ed. rev. e atual. - [Brasília]: Conselho Federal de Serviço Social, [2011]. Disponível em: < http://www.cfess.org.br/arquivos/CEP2011_CFESS.pdf >. Acesso em 16 de junho de 2018.

. MINISTÉRIO DA SAÚDE. Secretaria de Assistência à Saúde. Portaria/SAS/№55 de 24

de fevereiro $1999 . \quad$ Disponível em:

$<$ http://bvsms.saude.gov.br/bvs/saudelegis/sas/1999/prt0055 2402 1999.html >. Acesso em 16 de junho de 2019.

RESOLUÇÃO CFESS N. 218/de 1997 que Caracteriza o assistente social como profissional da saúde. [Brasília]: Conselho Federal de Serviço Social, [1999]. Disponível em: < http://www.cfess.org.br/arquivos/resolucao 383 99.pdf $>$. Acessado em 16 de junho de 2018.

CFESS. Parâmetros para Atuação de Assistentes Sociais na Política de Saúde. [Brasília]: Conselho Federal de Serviço Social, [2010]. Disponível em:<http://www.cfess.org.br/arquivos/Parametros para a Atuacao de Assistentes Sociai

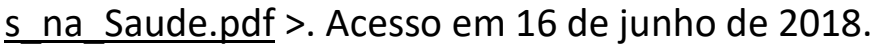

FONSECA, J. J. S. Metodologia da pesquisa científica. Fortaleza: UEC, 2002. Apostila.

GIOVANELLA, L. et al (Org.). Políticas e Sistema de Saúde no Brasil. Brasil: Fiocruz, 2008.

IAMAMOTO, M.V. O Serviço Social na contemporaneidade: trabalho e formação profissional. $5^{\circ}$ ed. São Paulo, Cortez, 2001.

IBGE. IBGE divulga o rendimento familiar per capita 2018. Disponível em: https://agenciadenoticias.ibge.gov.br/agencia-sala-de-imprensa/2013-agencia-denoticias/releases/23852-ibge-divulga-o-rendimento-domiciliar-per-capita-2018> acesso em 22 de novembro de 2019.

. Desemprego cai para 11,9\% na média de 2019; informalidade é a maior em 4 anos.. Disponível em: $<$ https://agenciadenoticias.ibge.gov.br/agencia-noticias/2012-agencia-de-noticias/noticias/26741desemprego-cai-para-11-9-na-media-de-2019-informalidade-e-a-maior-em-4-anos> acesso em 22 de novembro de 2019.

INSTITUTO NACIONAL DO CÂNCER. Registro Nacional de Doadores Voluntários de Medula Óssea (REDOME). Disponível em: <http://redome.inca.gov.br/o-redome/conheca-oredome/ > Acesso em 22 de novembro de 2019.

LAPORTA, T. Renda domiciliar per capita no Brasil foi de $\mathbf{R} \$ 1.373$ em 2018, mostra IBGE; G1. Disponível em: <https://g1.globo.com/economia/noticia/2019/02/27/renda-domiciliar-percapita-no-brasil-foi-de-r-1373-em-2018-mostra-ibge.ghtml> Acesso em 22 de novembro de 2019.

MARTINELLI, M.L (org.) Pesquisa qualitativa: um instigante desafio. São Paulo: Veras Editora, 1999

OLIVEIRA, F. Atenção à saúde: das caixas de Aposentadoria e Pensões ao SUS. Disponível em: $<\quad$ https://www.otempo.com.br/opiniao/fatima-oliveira/atencao-a-saude-das-caixas-deaposentadoria-e-pensoes-ao-sus-1.207270 > Acesso em 22 de novembro de 2019. 
PARANÁ. SESA/COSEMS/PR. Comissão Intergestores Bipartite do Paraná. Deliberação no 34 de 11 de maio de 1999. Normatização para encaminhamento de pacientes para tratamento Fora do Domicílio - TFD. Disponível em: https://www.saude.pr.gov.br/Pagina/CIBPRComissao-Intergestores-Bipartite-do-Parana acesso em 16 de junho de 2018.

REGISTRO BRASILEIRO DE TRANSPLANTES. Dimensionamento dos Transplantes no Brasil e em cada estado. São Paulo: Ano XXIV N4 Biênio, 2018-2019. Disponível em: <http://www.abto.org.br/abtov03/Upload/file/RBT/2018/Lv_RBT-2018.pdf >. Acesso em 12.11.2019.

SILVA, D.G.P. Recomendação Administrativa TFD Municípios. Disponível em: < http://www.saude.mppr.mp.br/pagina-343.html > Acesso em 16 de junho de 2019.

SILVEIRA, D. Brasil tem recorde de trabalhadores sem carteira assinada, mostra IBGE; G1. Disponível em:

$<$ https://g1.globo.com/economia/concursos-e-emprego/noticia/2019/01/31/brasil-temrecorde-de-trabalhadores-sem-carteira-assinada-mostra-ibge.ghtml>. Acesso em 22 de novembro de 2019.

UFPR. Comitê de Ética em Pesquisa (CEP). CAEE: 18880719.5.0000.0096. Parecer consubstanciado no 3.575 .827 . 